are given in the following table, and would seem to lend support to the above thesis:-

\title{
TABLE 3.
}

Fragility of Red Cells before and after Splenectomy.
CHILD.
\% of cONTROL. MOTHER at which hæmolysis commenced.

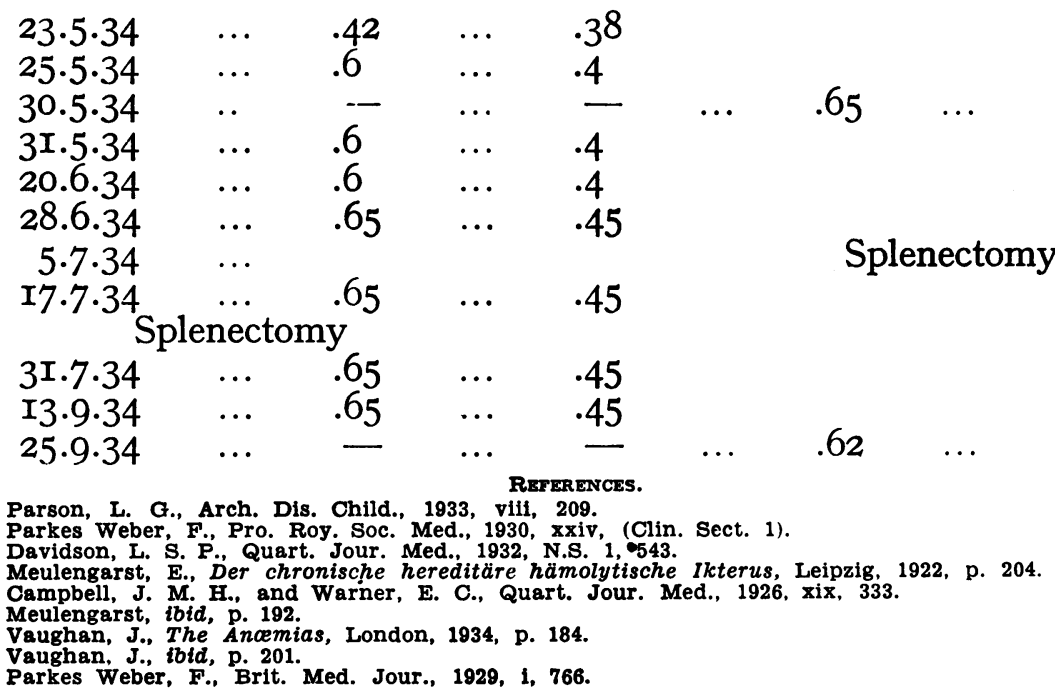

\section{OBSTRUCTIVE EMPHYSEMA DUE TO BRONCHIAL CARCINOMA.}

By H. V. MORLOCK, M.C., M.D., M.R.C.P.

(Physician, Miller General Hospital, City of London Hospital for Diseases of the Heart and Lungs, O.P. Department, Hampstead General Hospital.)

The patient, a man aged 46 years, presented himself with the following history: Six months previously, an unproductive cough had developed and had continued ever since. Three months later, pain appeared in the left chest, of a dull aching character, more or less continuous, which was increased on deep inspiration. There had been no hæmoptysis, nor had any loss of weight been noted.

Previous history revealed nothing of importance.

Condition on examination: Healthy looking man; face, mouth, throat, neck, presented nothing abnormal. No glands palpable in supraclaricular fossæ or axillæ. Heart, normal in size and position to palpation and percussion; sounds normal. Lungs: Left thorax a little fuller than right. Left moves less than right. Tactile fremitis diminished over left lung. On percussion, both lungs appeared equally resonant in all areas. On auscultation over right lung nothing abnormal heard. Over the whole of left lung, breath sounds completely absent. No bell sound, or succussion splash elicited.

These physical signs could be interpreted in one of two ways: either as a pneumothorax, or as an obstructive emphysema due to partial occlusion of the left main bronchus.

Usually with a spontaneous pneumothorax, the heart is displaced away from the lesion, but quite commonly, owing either to a fixed mediastinum or to the 
pressure in the pneumothorax not being high, the heart is not displaced. Hence, in this case, the fact that the heart was normal in its position could not be used as a point against the diagnosis of pneumothorax.

The "Bell Sound" and a succussion splash are so often absent in pneumothorax, that their absence in this case was no argument against the diagnosis of a pneumothorax.

It was therefore necessary to reconsider the history, to see if that could help in the differentiation of the two conditions. In the first place the age and good general condition of the patient gave no weight to either possibility.

The comparatively insidious onset of the pain and dyspnœea was definitely in favour of obstructive emphysema, for although the symptoms of the onset of a spontaneous pneumothorax may be occasionally so slight that the patient is not conscious of anything abnormal, the onset is commonly abrupt, and the patient is aware of the sudden appearance of pain and dyspnoa.

The duration of the illness was in favour of an obstructive emphysema, for a spontaneous pneumothorax usually tends to improve in a few weeks, although one sees occasionally cases which extend over a period of months or even years.

On the whole the clinical evidence was in favour of an obstructive emphysema.

Radiology would naturally be expected to give some help in the differential diagnosis, as indeed it did, for the skiagram showed that there was no pneumothorax in the left plural cavity, but that the left lung was more translucent than the right, and that in the left hilar region there was a shadow the size of a pullet's egg.

In order to complete the diagnosis, it was necessary, however, to see the obstructing body and to ascertain its nature. For this purpose I bronchoscoped the patient and observed a new growth where the left upper lobe bronchus leaves the left main bronchus; a piece of this removed for section showed it to be an "oat cell" carcinoma.

It is usual and well recognised that a bronchial new growth will occlude a bronchus and give rise to collapse of the lung distal to the occlusion, but it is not so well recognised that partial occlusion will produce an obstructive emphysema. The mechanism of the production of this emphysema, as pointed out by Chevalier Jackson, is quite simple, and could be seen in this case at the time of the bronchoscopic examination, namely, that during inspiration the bronchi expanded so that the bronchial walls pulled away from the attached margin of the new growth, and allowed air to enter the distal lung. During expiration the bronchi contracted on to the growth, thus trapping air which had entered during inspiration, and so, with its gradual accumulation, ultimately giving rise to the condition of obstructive emphysema.

As the growth increases in size, it will occlude the bronchi during inspiration as well as during expiration, and thus the emphysema, through absorption of the trapped air, will give place to collapse of the whole lung with corresponding changes in the physical signs (impaired percussion note, absent breath sounds and displacement of the heart towards the obstructed side). In some cases, however, the growth will ultimately completely occlude one bronchus, while it may only occlude the other during expiration, so that obstructive emphysema develops in one lobe of a lung (percussion note good, breath sounds absent) and collapse in the other (impaired percussion note and absent breath sounds). 